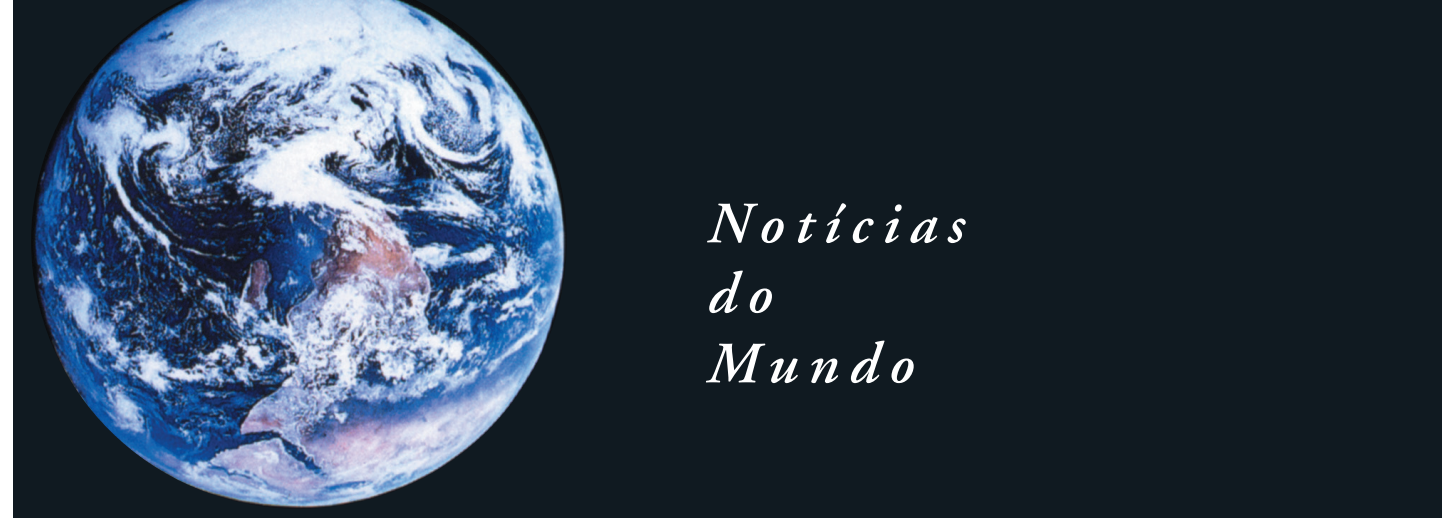

PRECARIADO

\section{Uma nova classe social ou o proletariado que se transforma?}

De repente, as ruas foram invadidas por descontentes. De início, eram alguns poucos milhares em São Paulo; protestavam contra o preço das passagens de transporte público. Em três semanas, mais de 100 cidades viram suas ruas tomadas por manifestantes, que somavam, segundo estimativas da época, mais de dois milhóes de pessoas. Quem eram eles? AndréSinger, professor da Universidade de São Paulo (USP), utilizou dados de institutos de pesquisa de opinião num artigo publicado na revista Novos Estudos e sugeriu que as manifestaçôes, principalmente no seu auge, eram compostas por uma classe média tradicional inconformada com diferentes aspectos da realidade nacional e por trabalhadores, em geral jovens, com emprego formal, de baixa remuneração, alta rotatividade e condiçōes precárias de trabalho. Singer lembra que os de renda familiar mensal até cinco salários mínimos, respondiam por cerca de $50 \%$ dos manifestantes.

Semelhante ao observado em outros países, principalmente da Europa, as manifestações no Brasil em junho de 2013 colocaram em evidência uma frustração geral com governos e com a política. Segundo André Singer, a maior parte dos manifestantes, apesar da escolaridade alta que os colocaria na classe média tradicional, em termos de renda salarial fazia parte de um novo proletariado, o precariado.

NOVA CLASSE SOCIAL Resultado da junção das palavras proletário e precário, o termo precariado suscita ainda muitos debates sobre o que realmente representa. Um grupo importante, no qual se destacam o sociólogo francês Robert Castel e o professor de economia inglês Guy Standing, considera o precariado uma nova classe social formada por profissionais, geralmente jovens qualificados, que enfrentam condições de trabalho cada vez mais precárias. Castel, falecido em março último, já discutia a precarização da condição salarial no livro $A s$ metamorfoses da questão social: uma crônica do salário, lançado na França em 1995. Em entrevista à Revue d'Information Sociale, em 2010, Castel insistia: "a situação não melhorou... o fenômeno da precarização permanece importante e parece ter sido ocultado pelo problema do desemprego... muitos continuam a trabalhar em condições abaixo do que foi e do que ainda é considerado um emprego".

Para Standing, o precariado é uma nova classe social, emergente e hete- rogênea, composta pelos que não têm educação ou status para compreender a situação e ouvem neofascistas; pelas minorias de imigrantes e deficientes, que estão perdidos e podem explodir; e por jovens educados que não têm futuro e que não aceitam propostas políticas da direita ou da esquerda. Standing identifica três características comuns a esses grupos: o emprego é casual e não lhes dá um senso de identidade profissional; os salários são muito baixos, com perda de benefícios eé necessário fazer muitas coisas não remuneradas (preparar currículo, procurar constantemente emprego, passar por treinamento etc); e faltam direitos a benefícios além do salário, como pensões, seguro-saúde e licença-maternidade. Autor do livro O precariado - a nova classe perigosa, Standing, que é ex-diretor da Organização Internacional do Trabalho (OIT), afirma que o precariado é a primeira classe social com nível de educação e qualificação acima do exigido pelo trabalho: "a pessoa tem grau universitário, mas trabalha como garçom".

POLÊMICA Mas há controvérsias em relação a algumas colocações de Standing. Nomes como os dos professores Ruy Braga e Giovanni Alves, no Brasil, e Peter Alexander e Edward Webster, na África do Sul, consideram que o precariado não é uma classe nova e sim uma camada do 


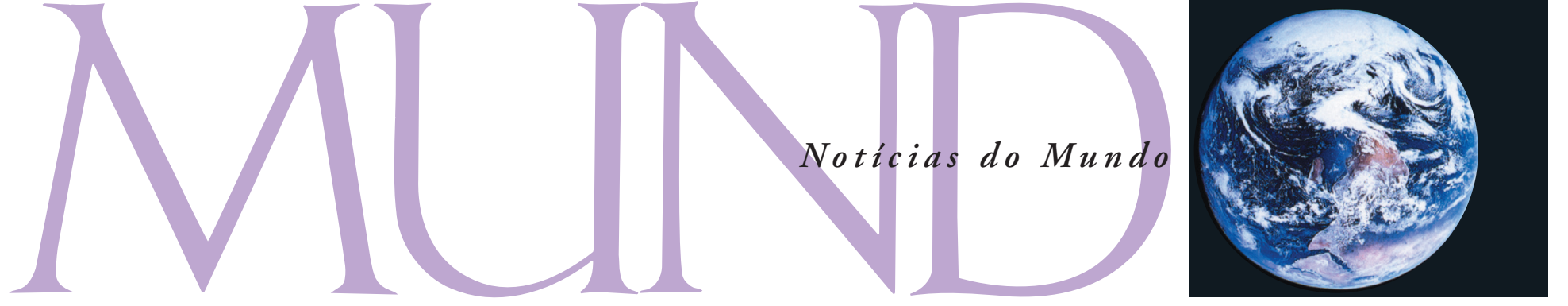

proletariado. Ruy Braga, professor da USP, aponta que o proletariado precarizado existe desde os primórdios do capitalismo histórico. Autor do livro A política do precariado: do populismo à hegemonia lulista, Braga remete a Karl Marx para delimitar o conceito de precariado como sendo a superpopulação relativa, excluindo-se os trabalhadores qualificados e a população pauperizada; ou seja, o precariado é formado pela camada da população latente, flutuante e estagnada. O conceito de superpopulação relativa (ou exército industrial de reserva) foi cunhado por Marx na segunda metade do século XIX. A população flutuante é a parte da classe trabalhadora formada pelos que entram e saem do mercado de trabalho, pois são contratados e demitidos muito rapidamente pelas empresas; a população latente é composta por trabalhadores muito jovens que estão no campo e migram para a cidade, mas ainda não ingressaram no mercado formal; já a população estagnada engloba trabalhadores submetidos a condiçôes absolutamente degradantes e que recebem salários baixíssimos. Para Braga o precariado é a fração mais numerosa e mais explorada da classe trabalhadora, mantida na periferia do sistema capitalista.

Giovanni Alves, sociólogo e pro- fessor da Universidade Estadual de São Paulo (Unesp), concorda que o precariado não é uma classe nova mas "inclui apenas jovens adultos altamente escolarizados, desempregados ou inseridos em relaçôes de trabalho e vida precárias". Segundo ele, "evidências empíricas demonstram efetivamente que esse é o perfil da juventude trabalhadora no seio dos novos movimentos sociais de rebeldia, tanto na Europa e Estados Unidos, quanto no Brasil".

Outra divergência é quanto ao perigo do precariado. Enquanto Guy Standing considera o precariado uma classe perigosa por ser massa de manobra para grupos de direita, Ruy Braga considera que trata-se de uma classe progressista: "luta para conservar direitos sociais e proteger conquistas dos trabalhadores, protegendo-se do ataque conservador aos direitos dos trabalhadores". Por outro lado, Alves defende que, politicamente, o precariado tem caráter dual, intrinsecamente contraditório: "muitos integrantes do precariado cultivam aspirações fetichistas de consumo e adotam o individualismo competitivo próprio do ethos burguês, mas estão profundamente imersos na condição de proletariado".

CAPITAL EM CRISE, TRABALHO PRECÁRIO Visto COMO uma camada do proletariado ou como nova classe social, o precariado é consequência do neoliberalismo e da globalização do capital. Sucessivas crises do capital, como a crise do México, em 1994, da Rússia em 1998 e a crise econômica de 20082009, que começou nos Estados Unidos e se alastrou por vários países da Europa, afetaram principalmente pessoas que constituem o grande contingente de reserva de mão de obra. Elas se viram destituídas das garantias sociais relativas ao vínculo empregatício, como estabilidade de emprego e renda e a representação política. Ou seja, as garantias conquistadas na Europa e nos Estados Unidos, sobretudo após a Segunda Guerra Mundial, vêm sendo negadas aos que ingressam no mercado de trabalho atualmente.

Leonor Assad 